\title{
Considering How Tertiary Education Providers Can Best Support the Mental Health and Wellbeing of their Students
}

\author{
Wade Limpus \\ Disability Services Coordinator \\ Tracey Carlyon \\ Teaching \& Learning Coach \\ Wintec
}

\begin{abstract}
The topic of mental health and wellbeing is currently prevalent in society and widely represented in the media. Sometimes anxiety and depression, which are disorders with diagnostic criteria, challenge mental health and wellbeing and pose problems for society. Given this, and the added pressures of tertiary study, it is important to learn more about how to best support student mental health and wellbeing now and in the future. This article reports on a study based in Aotearoa/New Zealand, which focussed on understanding mental health and wellbeing, specifically in the tertiary education sector. The aim of the study was to develop a clear understanding of how tertiary providers can best respond to the mental health and wellbeing of their students. Data were gathered from 115 members of the general population to understand how mental health is perceived, gauge perceptions of future trends and develop a plan to support tertiary communities. Key findings suggest the tertiary environment has a significant impact on student mental health and wellbeing, and some providers may be falling short of meeting shifting needs. In addition, participants predicted that anxiety and depression will continue to impact most students, and in order to respond effectively, tertiary providers need to take a much more co-ordinated approach in order to support their students' mental health and wellbeing.
\end{abstract}

\section{Introduction}

Mental health and wellbeing is a topic that is widely represented in media, just as conditions which challenge wellbeing, such as anxiety and depression, are increasing. Given the added pressures of tertiary study, it is therefore important to learn more about how best to support students' mental wellbeing now and in the future. This article reports on a study based in Aotearoa/New Zealand, which focussed on mental health and wellbeing in the tertiary education sector. Unlike much of the previous research, the study focussed specifically on mental health and wellbeing rather than mental health per se. The aim of the study was to develop a clear understanding of how tertiary providers can best respond to the changing mental health and wellbeing of their students. Data were gathered from 115 members of the general population to understand how mental health is perceived, gauge perceptions of future trends and design a plan to support students' mental health and wellbeing.

The article first explores mental health and wellbeing and how tertiary providers in Aotearoa/New Zealand are currently responding to students' mental health and wellbeing. Next, an explanation of the research design is provided. Findings are presented and discussed under the following headings derived from data analysis: varied definitions of mental health; impact of the tertiary environment on mental health and wellbeing and how tertiary providers can respond. Next, limitations of the study are discussed, followed by a conclusion.

\section{Mental health}

The Mental Health Foundation (MHF) estimates that 242,000 people, or 5\% of New Zealanders, are living with a disability caused by psychological and/or psychiatric conditions (MHF Quick Facts and Stats, 2014). Health statistics in New Zealand clearly show anxiety and depression as having a key influence on an individual's wellbeing. The MHF 2014 survey highlighted that $14.3 \%$ of New Zealand adults (more than half a million people) had been diagnosed with depression and $6.1 \%$ (more than 200,000 people) with anxiety disorders (MHF Quick Facts and Stats, 2014). Further to this, the 
Prime Minister's Mental Health Project reported that "depression and anxiety are quite wide-spread: one in five young New Zealanders will be affected by depression by the age of 18; almost one in five meet the criteria for an anxiety disorder by age 19" (Mental Health Foundation, 2014). Adding to these statistics, UNICEF reports that New Zealand has by far the highest youth suicide rate in the developed world (Fyers, 2017), highlighting the urgency to reduce such statistics.

The New Zealand Union of Students' Association (NZUSA) (2018) suggests that entering the tertiary education system can add to existing pressures for students as well as trigger existing mental health challenges and/or develop new ones. Their research, Kei Te Pai, highlights that young tertiary students are experiencing higher stress levels than young 'non-students' (New Zealand Union of Students' Association, 2018). Further to this, the report shows that $19 \%$ of tertiary students are currently seeing a mental health professional and $45 \%$ of the tertiary population have seen a mental health professional at some stage (New Zealand Union of Students' Association, 2018). It is clear that students face many barriers in the tertiary education environment, and mental health and wellbeing impacts on their academic success (Andrews \& Chong, 2011; New Zealand Union of Students' Association, 2018). Andrews and Chong (2011) add that many students entering tertiary study who may already be experiencing mental health wellbeing issues can then find these are exacerbated by the stress of academic study. Despite this, research has shown that the majority of students who have access to mental health services available through their tertiary provider choose not to use this support. The reasons for not pursuing this support include: students wanting to handle it by themselves, feeling they don't need it, embarrassment, high costs, and wait times (New Zealand Union of Students' Association, 2018). Further to this, although the amount of counselling accessed does not directly mirror mental health and wellbeing levels, it is important to note that counselling used by students at New Zealand's universities has grown nearly 25\% since 2015 (New Zealand Union of Students' Association, 2018).

While it is important to acknowledge that mental health conditions affect people in different ways and to varying degrees, which many are able to manage effectively, the research highlights some disturbing statistics.

\section{How tertiary providers are currently responding to students' mental health and wellbeing}

Public websites show that tertiary providers in New Zealand are currently responding to mental health and wellbeing in a variety of ways. For example, Manukau Institute of Technology, The University of Waikato and The University of Auckland all advertise a range of similar services including counselling, health and wellbeing through to accessibility services. While the University of Otago lists similar services, in addition they provide the option of booking appointments with mental health clinicians.

It is important to note here that support, such as counselling, is often accessed and managed through health centres which may or may not be offsite. In addition to these examples of support available to students, there are usually options to reduce study from full-time to part-time, which can alleviate stress. In addition to providers responding to and supporting the mental health and wellbeing of their students, there are some guidelines and principles outlined at national level. One example of this is the government has budgeted $\$ 10.49$ million over three years for counselling for 18-25 year olds (Beehive.govt.nz , 2018). While this pilot program is the first step in making counselling free for all under-25s, it is still too early to see any real benefits.

Recent research by NZUSA also suggests increased counselling services as a first priority to best develop support for tertiary students (New Zealand Union of Students' Association, 2018). Also, increasing information and providing greater opportunities for professional development for staff have been suggested as ways of supporting students' mental health wellbeing within tertiary environments (DiPlacito-DeRango, 2016; Fossey et al., 2017). At a broader level, the Tertiary 
Educational Strategy recognises "government, TEOs, and schools need to work together to support at-risk young people into tertiary education, higher levels of study and on to employment" (Ministry of Education, 2018.).

Given the diverse ethnic population of Aotearoa/New Zealand, models for understanding Māori health, such as Te Whare Tapa Whā, may offer some solutions for tertiary providers. Developed by Mason Durie, the holistic model includes four equal sides of a wharenui (communal house) to illustrate dimensions of Māori wellbeing. These dimensions comprise Taha tinana (physical health), Taha wairua (spiritual health), Taha whānau (family health), and Taha hinengaro (mental health). It is considered that if one of the four dimensions is missing or in some way becomes damaged, a person may become unwell (Ministry of Health, 2017). While this model has been derived from a Māori perspective, the model is relevant for all students and as such can be applied in the tertiary setting.

The literature in this section illustrates some disturbing statistics pertaining to the mental health and wellbeing of the population of Aotearoa/New Zealand. It highlights depression and anxiety, in particular, as two conditions that challenge mental health and wellbeing. Added to this, studying at tertiary level has been shown to be a stressful time for students and, as a result, there is increasing pressure being placed on tertiary providers to respond in a timely and appropriate manner. Currently, the government has a number of guidelines and initiatives which are aimed at providing direction for tertiary providers to respond to student mental health and wellbeing; however, statistics indicate these may be insufficient, no longer appropriate or lacking in priority. Clearly the need to support students' mental health and wellbeing requires some urgency from tertiary providers.

\section{Research design}

The research was positioned within an interpretive framework, while using a case study methodology. Case studies are an appropriate methodology when researchers wish to explore a program or concept (Creswell, 2009), such as mental health and wellbeing. This methodology enables researchers to gain a clear understanding about a concept as it is focussed on portraying "participants' lived experiences of, thoughts about and feelings for a situation" (Cohen, Manion, \& Morrison, 2011, p. 254). The overarching research question that guided the research was: how can tertiary education providers in Aotearoa/New Zealand best respond to students' mental health and wellbeing in the future?

Although the research was generally qualitative in nature, a mixed methods approach was adopted to gather both qualitative and quantitative data to best answer the research question. A number of researchers support using a mixed method approach and suggest that combining both qualitative and quantitative data may give a better understanding than using one method alone (Bryman, 2001; Cohen, et al., 2011; Neuman, 2006). Both quantitative and qualitative data were gathered from an online survey (Appendix A) and qualitative data from semi-structured interviews (Appendix B). Initial ideas and themes that emerged from the online survey were able to be explored in greater depth during the interviews which, as Neuman (2006) suggests, adds robustness to research.

The online survey was available to the public and made available through email communications, word of mouth and Facebook. Included in the online survey were multiple choice questions, rating scales and a matrix layout. The matrix included conditions to select from, which were constructed from the first author's experience as a disability co-ordinator in a tertiary institute. Although not all options listed were recognised as 'mental health' conditions, those included were considered to potentially impact on students' mental wellbeing. At the end of the survey there was an open question to allow participants to add any further comments. The online survey was used to gather data that would identify any trends concerning mental health and wellbeing and to create some tentative themes to be explored in the interviews. During these interviews, the participants were able to construct, clarify and develop their ideas (Cohen et al., 2011; Radnor, 2001) about mental health and wellbeing. In total, 115 members of the public participated in the study by completing the online 
survey who classified their gender as; male -21 , female -92 , other -1 , no response -1 . The age and ethnicity of these participants are set out in Tables 1 and 2 below.

Table 1: Age of participants in online survey

\begin{tabular}{|l|l|}
\hline $18-20$ & 9 \\
\hline $21-30$ & 21 \\
\hline $31-40$ & 24 \\
\hline $41+$ & 56 \\
\hline Non-response & 5 \\
\hline
\end{tabular}

Table 2: Ethnicity of participants in online survey

\begin{tabular}{|l|l|}
\hline NZ European & 86 \\
\hline Māori & 13 \\
\hline Pasifika & 2 \\
\hline Asian & 6 \\
\hline Other & 8 \\
\hline
\end{tabular}

Four individuals from different tertiary providers also participated in a semi-structured interview. These four participants all held student support roles connected in some way to student disability services in their respective institutes. To protect the participants' identities, those from the online survey were all given a number e.g. PN108 and those from the semi-structured interviews given a pseudonym (Josh, Caleb, Sue and Luke).

Full ethics approval to undertake the research was approved by Wintec's Human Ethics in Research Group.

\section{Findings}

Findings from the study are presented under the following three sub-headings: varied definitions of mental health, impact of the tertiary environment on mental health and wellbeing, and how tertiary providers need to respond. These themes were derived from an analysis of data from the survey and interviews.

\section{Varied understandings and definitions of mental health}

To learn more about the participants' understanding and definitions of mental health and wellbeing and conditions that may impact this, they were asked a range of questions. These included questions about conditions participants were most familiar with, those they had personal experience of, and how they individually defined mental health. Survey data showed that anxiety and depression were the two most common conditions that the participants were familiar with. This data also showed they were not as familiar with other conditions such as ADHD, asperger's, autism, dyslexia, epilepsy, and head injury. PN050 shared their view about an increase of primary and secondary students "who suffer from debilitating anxiety disorders". Furthermore, PN091 noted that in the last 10 years "the number of students I've seen with depression, anxiety, learning difficulties, different ways of being (socially awkward or 'different'), emotional problems has increased hugely". Notwithstanding these comments, it was pointed out by PNOO3 that "a mental health problem like depression can often be successfully treated and recovered from, unlike disabilities".

Further to this, Table 3 below shows the responses when the participants in the survey were asked to identify those conditions they had personally experienced themselves. 
Table 3: Conditions personally experienced

\begin{tabular}{|l|l|}
\hline Condition & $n$ \\
\hline ADHD & 3 \\
\hline Anxiety & 67 \\
\hline Asperger's & 2 \\
\hline Autism & 2 \\
\hline Depression & 63 \\
\hline Dyslexia & 6 \\
\hline Epilepsy & 3 \\
\hline Head injury & 10 \\
\hline Other & 17 \\
\hline None & 28 \\
\hline
\end{tabular}

Anxiety and depression are shown as being the conditions that survey participants had most personal experience of. Additionally, Table 3 illustrates that other conditions that could be considered major players, such as autism, few participants had personally experienced. Although the four participants in the interviews were not asked about conditions they had personally experienced, they also identified anxiety and depression as conditions they were most familiar with. When asked about this, Sue responded: "Obviously, anxiety and depression are probably the main ones", and Jeff pointed out "probably anxiety would be one of the biggest ones".

Undoubtedly, experiences influenced how the participants were able to define mental health, and this was evident from the range of responses received. In both sets of data, findings revealed that personal definitions differ considerably. PNOO5 described mental health as "having the resilience and ability to cope with a variety of situations", others, however, considered mental health in a different light. The following definitions are indicative of this: [mental health can be defined as] "an imbalance in emotional, mental and psychological wellbeing" (PNO30), and "a black cloud hanging over your head. No sunshine in sight" (PN059). Additional definitions included: "psychological stresses" (PNO90) and "depression and general anxiety" (PN035).

Defining mental health for some participants was not simply categorising a condition as either mental or physical. For example, participant PNOO4 said, "Mental health is not the opposite of mental illness." However, participant PNO85 stated that mental health is "the opposite of mental illness, and PN013 commented, "It's a broad term covering anything that's not physical health." It was interesting to note, additional views focussed on the stigma that can be associated with the term. An example of this was provided by $P N O 45$ who expressed their frustration towards mental illness being referred to as mental health: "I understand a desire to reduce stigma but calling something the opposite to what it is doesn't reduce stigma."

When asked to define mental health, the responses from participants in the interviews were all in the same realm of emotional wellbeing and one's ability to cope with stress. However, their definitions were more consistent as a group and were reflective of emotional wellbeing, which was not surprising, given they were all working in student support roles within disability services in their respective institutes. The following examples are reflective of this. [Mental health can be defined as] "a person living an ordinary life that occasionally becomes unwell" (Josh); "you can cope with life well, with the normal stresses of life and lead a happy and fulfilled life" (Sue). 
Understandably, mental health, and conditions which impact on mental health and wellbeing, can be sensitive topics, which some may find difficult to talk about. Findings presented here certainly bring to light that people hold different understandings and definitions of mental health and indicate that these beliefs have been influenced by their personal feelings and experiences. In general, however, data suggested that definitions of mental health could fall under one of two broad categories: an individual's resilience or ability to cope with stress; or a condition. In addition, some participants expressed the desire for mental health to be clearly defined as different from mental illness. It could be considered that such varied definitions and understandings of mental health may in fact be contributing to the decline in mental health and wellbeing, particularly for tertiary students. Welldefined meanings or definitions are important, firstly to gain a clear understanding of what is being communicated and secondly to use as a starting point to consider how best to respond to mental health and wellbeing in tertiary education.

The data highlighted anxiety and depression as increasing and as conditions that have a significant impact on an individual's mental health and wellbeing. Furthermore, aligned with Kei Te Pai, they suggested an increase in tertiary students experiencing anxiety and depression, in many cases also requiring support for mental health and wellbeing from their providers.

\section{The impact of the tertiary environment on student mental health and wellbeing}

Findings from both sets of data brought to light that participants believed anxiety and depression are most likely to impact the mental health and wellbeing of tertiary students.

Table 4: Predicted most common mental health conditions in tertiary education in five years' time

\begin{tabular}{|l|l|}
\hline Condition & $\boldsymbol{n}$ \\
\hline ADHD & 31 \\
\hline Anxiety & 95 \\
\hline Asperger's & 27 \\
\hline Autism & 32 \\
\hline Depression & 95 \\
\hline Dyslexia & 29 \\
\hline Epilepsy & 8 \\
\hline Head Injury & 10 \\
\hline Other & 6 \\
\hline
\end{tabular}

As shown in Table 4, conditions including autism, ADHD, dyslexia and asperger's were frequently considered as having the potential to impact student mental health and wellbeing in the future. In addition to these conditions, survey participants noted eating disorders, addictions, self-harm and Irlen's syndrome. Comments from participants included:

Studying is stressful which can trigger issues that people thought they were well past (PN62).

We are finding a lot of disruptive behaviours in class because of this and trying to manage the situations carefully and safely can be very tricky (PN110).

It is unfortunate that support services have suffered and therefore students have missed out and their mental health and wellbeing has suffered. It has become the ambulance at the bottom of the cliff service in many cases (PNO05). 
Notably there was a very high response to 'anxiety' and 'depression' with comments such as:

tertiary education can trigger mental distress due to: it being a new environment with lots of new social expectations; home sickness; culture shock; education contains high expectations to succeed, to accept correction, judgement, feedback and making mistakes; past negative education experiences; bullying at school etc. etc. PN045

Caleb pointed out that the tertiary environment, exams and meeting deadlines "can exacerbate the issue". The following comment from Luke was indicative of the other three interviews: "I do think that anxiety and depression are probably going to increasingly impact on our students." Josh discussed this further and commented about the importance of supporting students who exhibit undesirable behaviour, such as being disruptive in class as a result of anxiety, as opposed to taking a punitive approach, "They're anxious now and it's because they're anxious that these things are all coming through."

Further to this, Luke discussed social anxiety disorders, which he believed will be more prevalent in the future. He recalled teachers and social work staff at schools reiterating and suggesting anxiety is "massive. It's huge with young people". He pointed out that while students have never been more connected online, with this can come isolation from social contact, and commented, "There's some correlation with growth in social media and with young people experiencing anxiety." Aligned to this, Josh suggested that having a mental health condition "seems to be the social norm". Luke also drew attention to the impact that different learning spaces, such as large open environments, can have on students. He pointed out that some of these learning environments do not suit everyone and can increase stress levels for many students. Further indication that anxiety and depression are anticipated to influence future mental health and wellbeing in tertiary education was provided by Sue who felt that there would also be an increase in foetal alcohol syndrome and $\mathrm{P}$ babies.

Data here suggest studying at tertiary level can be stressful for students, in addition to which more seem to be entering their study with existing mental health issues. Given this, it seems timely to consider different ways tertiary providers can respond to support their students' mental wellbeing.

\section{Ways tertiary providers can respond}

Table 5 below shows the responses from participants in the survey when they were asked to rank from a list of services how much they anticipated tertiary providers should proactively support and respond to mental health and wellbeing.

Table 5: Ways tertiary providers should respond

\begin{tabular}{|l|l|l|l|}
\hline support & $\begin{array}{c}\text { a great } \\
\text { deal }\end{array}$ & \multicolumn{1}{|c|}{ some } & none \\
\hline Academic support & 75 & 31 & 1 \\
\hline Connection to community support & 75 & 31 & 2 \\
\hline Counselling services & 90 & 18 & 0 \\
\hline Forming and sustaining positive relationships & 80 & 26 & 0 \\
\hline Pastoral care & 62 & 42 & 4 \\
\hline Provision of wellbeing and suicide prevention awareness & 91 & 15 & 1 \\
\hline Provisions made by tutors & 68 & 37 & 3 \\
\hline
\end{tabular}

Responses highlight that participants, in general, believe support for student mental health and wellbeing from tertiary providers is very important. 'Provision of wellbeing and suicide prevention awareness' along with 'counselling services' were thought to be required 'a great deal'; however, overall there was little difference in the importance given to each of the services. 
Responses varied about the future with many participants from the survey feeling under pressure because of a lack of resources and expertise to deal with mental health conditions. Others felt that tertiary providers need to acknowledge mental health and be sympathetic but stated that they did not believe it was "up to the tertiary sector to manage them. This sits outside the scope of core business" (PNO13). Participants also talked about support not being provider responsibility and how tutors need to know where to draw the line in communications with students. Participant PNO19 said, "It's important we create awareness around early detection and prevention." PNO39 agreed: "Creating an environment where it is ok to talk about it is important but also recognising that tutors/lecturers shouldn't need to become counsellors." PN51 cautioned that "educators need to balance out their work so that they don't take mahi home".

Further suggestions of how tertiary providers could support mental health and wellbeing in the future included:

We need more staff trained in this area, and more support or training on connecting students with the right support people (PN11).

It would also be great to see more events that foster community spirit with the students (PN29).

Without wellbeing learning cannot take place. Educators need to understand the neuroscience behind learning so that they can teach to learn (PN44).

Induction processes at tertiary level should include protocols for identifying students experiencing anxiety and at risk of anxiety, with appropriate 'wrap around' support available to them (PN50).

During the interviews, participants were not provided with a list of services to rank but were instead asked to comment on how they believed tertiary providers should respond. Josh suggested the production of more visual information, such as posters or brochures, would be useful to direct people to help, and professional development for staff to support mental health and wellbeing. Caleb pointed out that some tutors could be overwhelmed about how to support a student with a mental health concern and suggested "it should be compulsory" for everyone to undertake professional development in the area. Along with two other interviewees, Luke also made reference to professional development for staff, and with two other interviewees, in particular around suicide awareness, argued for providers to have clear processes for this. He commented that "teaching staff need to have explicit awareness and training around how to recognise and support". While acknowledging the challenges of meeting individual students' needs, he felt that teaching staff should have the skills to adapt their teaching and be flexible to accommodate those students who may need support. He also suggested, "let's talk about it, let's bring it out in the open" and for tertiary providers to take a "whole of institution approach right through" with regard to mental health and wellbeing.

Josh suggested, however, that individualised support, as opposed to group support, was another strategy that tertiary providers could use. He pointed out, "why would they want to come along and talk about their issues in front of 20 people, people with mental health issues seem to be a little bit more guarded". He was encouraging of developing a culture where staff referred students to support, even if they were unsure who was the right person to refer them to. "Send them to one of us, we don't care." Sue suggested that tertiary providers should improve their communites' awareness of mental wellbeing and that reducing stigma is required to help prevent people from not coming forward for support. She added, "Maybe we need more mental health advisors, more counsellors on campus to deal with the increase of students wanting support."

In general, Josh felt that tertiary providers do not tell students about all the pressures in store for them and as such they run the risk of adding possible stress. Luke discussed the need for a more collaborative approach to be taken with regard to student wellbeing and suggested "having a voice at 
the management table is really critical. I think we are going to see more and more people affected by mental health and anxiety and depression". While he pointed out that most organisations had strategies for disability awareness, he believed they needed further budget and resource allocation and "awareness and responsiveness to mental health with explicit KPIs".

Both sets of data offer some useful solutions for tertiary providers to respond appropriately and adequately to support their students' mental health and wellbeing. Participants put forward ideas which suggested that a much more proactive, collaborative and holistic approach was required by tertiary providers. The framework below is a visual representation of all these ideas and shows how they interrelate and complement each other.

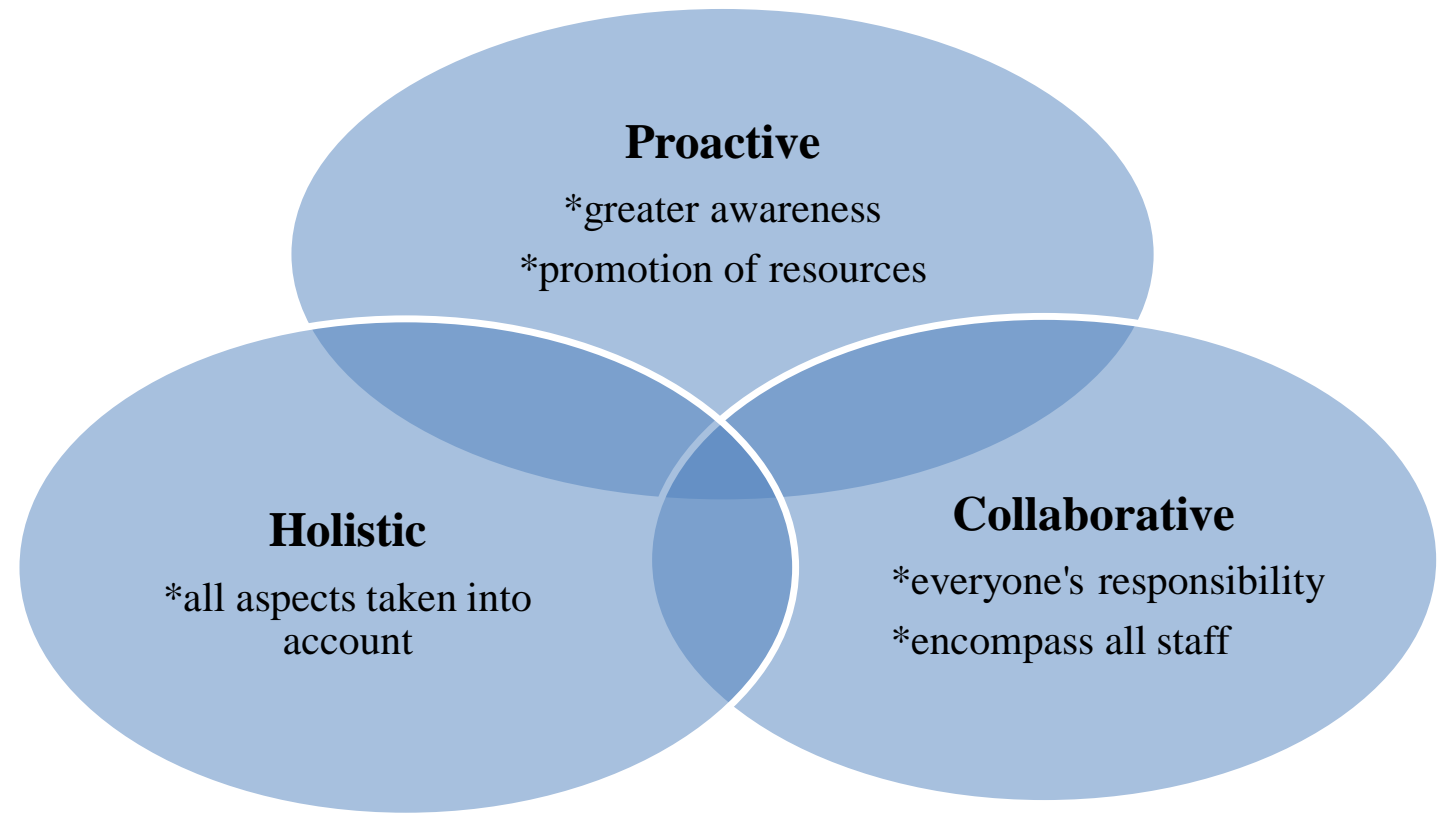

Figure 1: Framework to support student mental health and wellbeing in tertiary education.

Being more proactive includes creating greater awareness and understanding about mental health and wellbeing through increased promotion of existing resources and courses that are available (DiPlacito-DeRango, 2016). This includes resources such as counselling which is frequently accessed or managed through health centres. In addition, tertiary providers need to be more proactive about upskilling all staff about their own mental health wellness as well as that of their students. Aligned with other research such as Fossey et al., (2017) data highlighted that tutors, in particular, require greater understanding about mental health and wellbeing to help them recognise how best to work with students. Taking a more collaborative approach requires tertiary providers to understand that student mental health and wellbeing is everyone's responsibility and therefore it is necessary to encompass all staff. This means the mental health and wellbeing of students should not be the sole responsibility of individuals such as tutors, disability services or health centres. Furthermore, these data indicate that a more holistic approach to support is required, where all aspects of a student's wellbeing are taken into account. Clearly there are a range of factors which contribute to student mental health and wellbeing; therefore models such as Te Whare Tapa Whā, which support all dimensions of an individual, are useful frameworks to consider (Ministry of Health, 2017).

\section{Limitations of the study}

The authors acknowledge there were some limitations and potential bias to the study. First, because over half of the participants fell within the 41+ age group it could be considered there was a lack of student voice in the study. Second, the authors acknowledge the potential bias due to participants' personal experience or close contact with mental health and wellbeing. Next, while conditions such 
as dyslexia were included in the study, as they could potentially impact mental health and wellbeing, they are not mental health conditions per se. Also, because conditions which can impact mental wellbeing, such as anxiety and depression, are frequently self-diagnosed this could challenge the accuracy of some data. It would have been pertinent to ask the question, 'have you been medically diagnosed with any of the following conditions?'

\section{Conclusion}

It is not surprising that findings from the study reported on in this article suggest mental health and wellbeing is a sensitive topic of which people hold varied definitions and perceptions. What is surprising is how prevalent anxiety and depression are compared to other conditions that could be considered also to have a significant impact on mental health and wellbeing. As a response to this, and the added pressure of study, tertiary providers currently offer a range of support for students. However, information indicates this support varies somewhat between institutions and despite guidelines it seems tertiary providers may not be adequately prepared, or committed, to support student mental health and wellbeing both now and in the future.

Aligned with research such as Kei Te Pai (New Zealand Union of Students' Association, 2018), which suggest the mental health and wellbeing of our tertiary students is important, it seems that the pressure for providers to succeed has resulted in less focus being given to supporting students. While clearly greater focus is required on supporting students' mental health and wellbeing, the difficulty seems to be in how tertiary providers can achieve this. Research reported on in this article suggests that tertiary providers will need to take a more co-ordinated approach, which includes being more proactive, collaborative and holistic in the future. Furthermore, the authors suggest the predicted increase in students experiencing conditions that impact their mental health and wellbeing calls for urgent commitment and action by all tertiary providers in Aotearoa/New Zealand. 


\section{References}

Andrews, A., \& Chong, J. L. Y. (2011). Exploring the wellbeing of students studying at an Australian university. Journal of the Australia and New Zealand Student Services Association, 37, 9-38.

Beehive.govt.nz. (2018). Free counselling pilot for 18-25 year olds a step closer. Retrieved from https://www.beehive.govt.nz/release/free-counselling-pilot-18-25-year-olds-step-closer

Bryman, A. (2001). Social research methods. Oxford, England: Oxford University Press.

Cohen, L., Manion, L., \& Morrison, K. (2011). Research methods in education (7th ed.). London, England: Routledge/Falmer.

Creswell, J. W. (2009). Research design. Qualitative, quantitative, and mixed-methods approaches (3rd ed.). London, England: Sage.

DiPlacito-DeRango, M. L. (2016). Acknowledge the barriers to better the practices: support for student mental health in higher education. The Canadian Journal for the Scholarship of Teaching and Learning, 7(2), 15.

Fossey, E., Bigby, C., Chaffey, L., Mealings, M., Williams, A., Serry, T., ... Ennals, P. (2017). Supporting students with mental health issues and acquired brain injury: university teaching staff perspectives. Journal of the Australia and New Zealand Student Services Association, 49(April), 15-22.

Fyers, A (June 15th 2017). UNICEF report: New Zealand 34th out of 41 developed countries for child wellbeing. Stuff June 15th 2017 Retrieved from: https://www.stuff.co.nz/national/93583589/unicef-report-wellbeing-of-kiwikids-languishes-behind-other-developed-countries

Mental Health Foundation. Quick facts and stats 2014. (2014). Retrieved from https://www.mentalhealth.org.nz/ assets/Uploads/MHF-Quick-facts-and-stats-FINAL.pdf

Mental Health Foundation (2014) "Are our Kiwi kids alrght?" Media Release, 11 August. Retrieved from https://www.mentalhealth.org.nz/home/news/article/24/are-our-kiwi-kids-all-right

Ministry of Education, N. Z. (2018.). Tertiary education strategy 2014 - 2019. Retrieved from http://www.education.govt.nz/further-education/policies-and-strategies/tertiary-education-strategy/

Ministry of Health. (2017). Te Whare Tapawhā Maori Health model Hauora Maori.

Retrieved from: https://www.health.govt.nz/our-work/populations/maori-health/maori-health-models/maorihealth-models-te-whare-tapa-wha

Ministry of Health. (2016). The Prime Minister's youth mental health project. Retrieved from https://www.health.govt.nz/our-work/mental-health-and-addictions/youth-mental-health-project

Neuman, W. L. (2006). Social research methods. Qualitative and quantitative approaches (6th ed.). Boston, MA: Pearson.

New Zealand Union of Students' Association. (2018). Kei Te Pai? Report on Students' mental health in Aotearoa (pp. 1-151). Retrieved from NZUSA website: http://www.students.org.nz/mentalhealth

Radnor, H. (2001). Researching your professional practice. Doing interpretive research. Buckingham, England: Open University Press.

The authors may be contacted via:

tracey.carlyon@wintec.ac.nz

\section{Please cite this paper as:}

Limpus, W.\& Carlyon, T. (2019). Considering how tertiary education providers can best support the mental health and wellbeing of their students. Journal of the Australian and New Zealand Student Services Association, 27(2), $188-200$. https://doi.org.10.30688/janzssa.2019.08 


\section{Appendix A - Questionnaire}

1. What gender are you?

Male Female Other

2. Which age group are you within?

$18-20 \quad 21-30 \quad 31-40 \quad 41+$

3. What is your ethnicity/s?

NZ European Maori Pacific Is Asian Other

4. How would you define the term 'mental health'?

5. Which of the following are you most familiar with?

ADHD/Anxiety/Asperger's/Autism/Depression/Dyslexia/Epilepsy/Head injury/Other

6. Which of the following do you think will be the most common in adult education in five years' time.

ADHD/Anxiety/Asperger's/Autism/Depression/Dyslexia/Epilepsy/Head injury/Other

(You may select more than one option)

7. Which of the following have you personally experienced yourself?

(You may select more than one option)

ADHD/Anxiety/Asperger's/Autism/Depression/Dyslexia/Epilepsy/Head injury/Other

8. How much do you anticipate tertiary education providers should proactively support and respond to mental health?

(Select your choice for each category)

\begin{tabular}{|l|l|l|l|}
\hline & A great deal & Some & None \\
\hline $\begin{array}{l}\text { Provisions made by tutors } \\
\text { (e.g. upskilling for tutors \& classroom provisions) }\end{array}$ & & & \\
\hline $\begin{array}{l}\text { Pastoral care } \\
\text { (e.g. budgeting, transport, accommodation) }\end{array}$ & & & \\
\hline $\begin{array}{l}\text { Academic support } \\
\text { (e.g. essay writing, developing study skills) }\end{array}$ & & & \\
\hline $\begin{array}{l}\text { Connection to community support } \\
\text { (e.g. Autism New Zealand) }\end{array}$ & & & \\
\hline $\begin{array}{l}\text { Provision of well-being and suicide prevention awareness } \\
\text { (e.g. student events, access to support information) }\end{array}$ & & & \\
\hline $\begin{array}{l}\text { Counselling services } \\
\text { (e.g. School counsellors) }\end{array}$ & & & \\
\hline $\begin{array}{l}\text { Forming \& sustaining positive relationships } \\
\text { (e.g.opportunities to connect) }\end{array}$ & & & \\
\hline
\end{tabular}

9. Please add any further comments that you would like to make regarding mental health well-being in tertiary education. 


\section{Appendix B - Questions for interviews with Disability Services Coordinators}

1. What gender are you?

2. May I ask which age group you are within?
$18-20$
21-30
$31-40$
$41+$

3. What is your ethnicity?

4. How would you define mental health?

5. In your current role, what forms of mental health challenges are you familiar with?

6. Which of these forms of mental health do you see as being most prevalent in adult education in the next five years?

7. In what ways do you anticipate tertiary providers will need to support students with mental illness in five years' time?

8. In what ways do you anticipate tertiary providers should support Disability Services Coordinators in the next five years?

9. In what ways do you anticipate tertiary providers should support tutors and other support staff in the next five years?

10. Provision of wellbeing and suicide prevention awareness has been highlighted as a key support that tertiary providers should offer, what do you think this could look like?

11. Do you have anything further you wish to add? 